\title{
Improving Quality of Practical Teaching with the Reflection Diary Feedback Teaching Method \\ L Yang ${ }^{1}$, Y Niu ${ }^{1}$, T-C Li², F-X Li ${ }^{3}$, Y-H Hou ${ }^{3}$, S-M Xue ${ }^{1}$
}

\begin{abstract}
Objective: Feedback teaching is based on three guiding principles: systems theory, cybernetics, and information theory, summed up in the teaching reform practice.

Methods: It differs from traditional instill-based teaching methods, as student feedback is considered a core teaching activity; feedback teaching replaces a one-way transfer with a multi-directional transfer of information, where the teacher fully plays the role of theoretical guide, improving students' comprehensive ability.

Results: The "reflection diary" is a teaching tool that encourages students to reflect on their learned knowledge and the experience they acquire in clinical practice by recording their experiences in a diary. We required the nursing undergraduates to write reflection diaries in clinical practice, which are then read and analysed by professional teachers who provide feedback in a timely manner.

Conclusion: Experience has proven that the reflection diary feedback teaching method has positive impacts, fostering the development of the emotional processing and learning abilities that students need for their careers, while helping them develop their initiative, as well as their communication, analytical and problem-solving skills.
\end{abstract}

Keywords: Feedback, nursing undergraduates, reflection diary, teaching method

\section{Mejoramiento de la Calidad de la Docencia Práctica Mediante el Método de Enseñanza de Retroalimentación a Través de Diarios de Reflexión \\ L Yang ${ }^{1}$, Y Niu ${ }^{1}$, T-C Li ${ }^{2}$, F-X Li ${ }^{3}$, Y-H Hou ${ }^{3}$, S-M Xue ${ }^{1}$}

\begin{abstract}
RESUMEN
Objetivo: La enseñanza mediante retroalimentación se basa en tres principios guías - la teoría de sistemas, la cibernética, y la teoría de la información - resumidos en la práctica de la reforma de la enseñanza.

Métodos: Se diferencia de los métodos tradicionales de enseñanza basados en procesos de inculcación, ya que en este método la retroalimentación del estudiante se considera una actividad central en el proceso de enseñanza. La enseñanza por retroalimentación reemplaza la transferencia unidireccional de información con una transferencia multidireccional, en la que el profesor desempeña plenamente el papel de guía teórico, mejorando la comprensión por parte de los estudiantes.

Resultados: El "diario de reflexión" es una herramienta de enseñanza que estimula a los estudiantes a reflexionar sobre el conocimiento aprendido y la experiencia adquirida en la práctica clínica, mediante el registro de sus experiencias en un diario. Le pedimos a los estudiantes de
\end{abstract}

From: ${ }^{1}$ School of Nursing, Xinxiang Medical University, Xinxiang 453003, Henan, PR China, ${ }^{2}$ Department of Paediatrics, the Third Affiliated Hospital of Xinxiang Medical University, Xinxiang 453003, Henan, PR China and ${ }^{3}$ Department of Respiratory Medicine, the Third Affiliated Hospital of Xinxiang Medical University, Xinxiang 453003, Henan, PR China.
Correspondence: Dr S-M Xue, School of Nursing, Xinxiang Medical University, No. 601 Hongqi District Jinsui Road, Xinxiang 453003, Henan, PR China. E-mail: songmeixuecn@126.com 
enfermería escribir diarios de reflexión sobre la práctica clínica, que son luego leidos y analizados por profesores profesionales que ofrecen retroalimentación de manera oportuna.

Conclusión: La experiencia ha demostrado que el método de enseñanza de retroalimentación a través de diarios de reflexión tiene efectos positivos, por cuanto fomenta el desarrollo del procesamiento emocional y las habilidades de aprendizaje que los estudiantes necesitan en sus carreras, a la par que les ayuda a desarrollar sus iniciativas, así como sus habilidades para para la comunicación, el análisis y la solución de problemas.

Palabras claves: retroalimentación, estudiantes de enfermería, diario de reflexión, método de enseñanza

West Indian Med J 2017; 66 (2): 233

\section{INTRODUCTION}

Reflection comes from the Latin word "reflectere," which means that a mirror reflects the image of the entity, revealing the thought process behind hidden, unnoticeable experiences. Reflection refers to an internal review and exploration of issues of concern emerging from a person's experiences, as well as the process of putting the internal experience into words and clarifying its meaning (1). Complex scenarios generate the need for reflection, since uncertainty prompts the individual to study the situation and discover a solution to his or her plight. Academics believe that the concept of reflection is very important to critical thinking, insight and learning, and that it is the source of truth, knowledge and self-regulation (2). Reflection provides the opportunity for nursing students to make decisions as they explore the practice of nursing and learn to use clinical judgment (3), leading to in-depth and comprehensive thinking on both theory and practice and changing their clinical practice behaviours (4). Therefore, reflection skills must be developed during the university education process (5).

Forms of reflection include basic reflective evaluation, peer group discussions and written self-reflection (6). Reflective writing is considered to be a powerful strategy to learn from an experience (7), improving the individual's understanding and analytical capabilities (8). In the field of nursing education, reflective writing can be used to effectively develop critical thinking abilities (9, 10). Recording professional practice experience helps students to understand their experiences, respond to critical events (11), and manage professional pressures (12). Diaries are used to engage in reflective self-evaluation and to reflect on behaviour during the educational process (2). In the United States of America and Canada, the use of reflective diaries to promote reflection on clinical practice is one of the most commonly used methods for educators (13). In southern Ireland, 10\% of nursing educators encourage students to self-reflect using reflec- tive diaries and other methods (14). Studies have found that students are able to describe their experiences, but have difficulty making judgments based on their analysis of a situation and learning from their experiences; although the level of reflection is more superficial when they first begin to use this technique (15-17), the ability to reflect improves over time (4).

Feedback teaching differs from traditional instillbased teaching methods, as student feedback is considered a core teaching activity; feedback teaching replaces a one-way transfer with a multi-directional transfer of information, where the teacher fully plays the role of theoretical guide, improving students' comprehensive ability. The "reflection diary" is a teaching tool that encourages students to reflect on their learned knowledge and the experience they acquire in clinical practice by recording their experiences in a diary. In the present study, nursing undergraduates are required to write reflection diaries in clinical practice, which are then read and analysed by professional teachers who provide feedback in a timely manner. Experience has proven that the reflection diary feedback teaching method has positive impacts, fostering the development of the emotional processing and learning abilities students need for their careers, while helping them develop their initiative, as well as their communication, analytical and problemsolving skills.

\section{SUBJECTS AND METHODS}

Undergraduate nursing students in the 2004 and 2005 cohorts at our hospital were selected as research subjects, and included 57 students in the 2005 cohort and 50 in the 2004 cohort. All students were female, aged from 20 to 25 years old, and had been admitted to a five-year programme on the basis of a national college entrance examination. Using the before and after comparison method, the students in the 2005 cohort composed the experimental group, with the 2004 cohort serving as the 
control group. The students in the two groups were taught by the same instructor and same classroom teachers using the same curriculum. There were no statistically significant differences between the two cohorts in terms of age, gender, learning background or other characteristics $(p>0.05)$. The data were comparable.

A five-week clinical clerkship period took place during the eighth, ninth and tenth semesters to provide opportunities for clinical practice. In the 2005 cohort's clinical clerkship process, students were required to write reflection diaries in accordance with specific programme requirements and timely feedback was provided by a professional teacher. Students in the 2004 cohort control group were required to write reflection diaries during the clinical clerkship, but did not receive feedback. In the practice metaphase, the students in both groups completed practice behavioural scale assessments.

\section{Implementation method}

Students were required to record their own personal experiences, observed activities and feelings in clinical practice in a diary, at a rate of one diary entry every week. Reflection diaries were carefully read, marked, and classified by professional teachers, who summarized relevant issues and provided centralized feedback on the common problems reflected in the diaries. Individual feedback was provided on a few specific questions or ideas. Professional teachers handled the doubt and confusion expressed in the students' reflection diaries based on their own experience or using reference books; they comforted and encouraged students who expressed discontent, grievances, sadness or other negative emotions, and guided them toward positive and effective ways of coping.

\section{Evaluation method}

A questionnaire was developed by extracting the main indicators of reflective teaching practice from the "Clinical practice behaviour evaluation form for undergraduate nursing students" developed by Jian Wang. Nursing students in the 2004 and 2005 cohorts completed the questionnaire survey in the interim between clinical practice periods due to practical considerations. In the metaphase of clinical internship, trainees in the selected three teaching hospitals of the province constituted the survey subjects, of which 35 students were from the 2004 cohort and 42 from the 2005 cohort. A total of 77 valid questionnaires were obtained, representing a 100\% completion rate.

\section{Statistical analysis}

Using SPSS 13.0 software, survey data was entered into a database and analysed. Responses were analysed using $\chi^{2}$ tests.

\section{RESULTS}

A comparative analysis of the two groups of students' interim practice self-evaluations is presented in Table 1 . Table 1 shows that the differences between the two groups' knowledge application skills, professional emotion, learning ability and communication, analytical and problem-solving skills and other variables are statistically significant $(p<0.05)$. Group differences in the clarification of the rights and obligations of the patients, applica-

Table 1: Comparative analysis of interim clinical practice self-evaluation of the students in the two groups

\begin{tabular}{|c|c|c|c|c|c|c|c|c|}
\hline Item & $\begin{array}{l}\text { Grade } 200 \\
\text { Increased }\end{array}$ & $\begin{array}{l}05(n=42) \\
\text { Slightly increased }\end{array}$ & No increased & $\begin{array}{l}\text { Grade } 20 \\
\text { Increasec }\end{array}$ & $\begin{array}{l}4(n=35) \\
\text { Slightly increased }\end{array}$ & No increased & $\chi^{2}$ value & P value \\
\hline $\begin{array}{l}\text { Self-awareness of } \\
\text { professional role }\end{array}$ & 33 & 7 & 2 & 21 & 4 & 10 & 8.250 & 0.016 \\
\hline $\begin{array}{l}\text { Learning enthusiasm and } \\
\text { initiative }\end{array}$ & 30 & 6 & 6 & 16 & 6 & 13 & 6.255 & 0.044 \\
\hline Communication skills & 31 & 9 & 2 & 14 & 3 & 18 & 21.766 & 0.000 \\
\hline $\begin{array}{l}\text { Abilities of analysing and } \\
\text { solving problems }\end{array}$ & 32 & 6 & 4 & 15 & 5 & 15 & 12.072 & 0.002 \\
\hline $\begin{array}{l}\text { Clarifying the rights and } \\
\text { obligations of patients }\end{array}$ & 28 & 9 & 5 & 16 & 7 & 12 & 5.867 & 0.055 \\
\hline
\end{tabular}


bility of the nursing programme, coping skills, and other aspects of the students' abilities are not statistically significant $(p>0.05)$.

\section{DISCUSSION}

Without effective teaching effectiveness feedback channels, the teaching process is an "open-loop" system in which teaching is separated from learning. Introducing feedback teaching into teaching practice allowed for a timely exchange of information between teachers and students, making it possible to control the amount of information exchanged and achieving the best teaching results.

Reflection diary feedback teaching is in line with modern cognitive psychological theory, taking the relationship between teaching and learning into account in the teaching process; this method emphasizes the timely exchange and feedback of information between teachers and learners, with particular emphasis on a mutually cooperative relationship and interaction between teacher and students.

University teachers should strive to understand students' needs and characteristics through exchange and communication so as to effectively achieve their teaching goals. Reflection diaries provide the students with a space, without time or place limitations, in which they can be free to play with ideas and release their concerns, which establishes a special channel of communication between teachers and students. Reflection diaries allow students to progressively record the details of their experiences in clinical practice, creating a true reflection of overall student learning, life, thoughts and needs. Through the reflective diaries, teachers gain access to information that they are rarely able to access using conventional feedback teaching methods. Reflection diaries serve as a good tool for communication between teachers and students.

Students receive a systematic professional education at school, fully longing for profession knowledge and hoping to apply their knowledge in clinical practice to realize their own value. However, once they enter into clinical practice, they may not be psychologically or emotionally ready for the duties of routine and complex care; some students experience intense negative emotions. The problems that students encounter in their practice are likely to affect their love for the profession and their professional attitudes, as well as their ability to develop good work habits and set a professional image. Only when nursing students emotionally accept and love the nursing profession can a positive attitude toward learning and future work be formed. Therefore, it is very important for nurses to develop an appropriate professional attitude. Professional teachers' timely feedback through reflection diaries help students correct their cognitive biases, develop the appropriate values and recognize the status of the nursing profession, as well as its potential; they thereby come to appreciate the value and significance of nursing, as well as the role of the nursing profession in the medical field. This process stimulates their sense of expertise and promotes their love of the nursing profession, helping them form a healthy professional attitude. The results (Table 1) show that the difference between the two student groups in career self-awareness is statistically significant, which fully demonstrates the important role of feedback pedagogy.

The results of this study show that the differences between the two student groups in terms of communication skills, learning initiative, the ability to apply subject knowledge, problem identification and analysis, and problem-solving skills are significantly different. Traditional teaching activities tend to instill knowledge in students as a conclusion; this single-direction way of transmitting information places students in a passive learning role, producing a poor teaching effect. By writing a reflection diary, students engage in in-depth thinking and analysis of one week's work, continuously elevating their perceptual knowledge to conceptual knowledge, stimulating their learning initiative, tapping their learning potential and developing their ability to independently acquire knowledge. When they enter into clinical practice, some nursing students cannot flexibly apply book knowledge to clinical practice. Because of fear, they are cautious and do not know how to communicate with patients; for example, one student wrote, "The patient asked me the role of the drug. I did not know how to answer at the time. I was embarrassed to leave the ward. Then, I realized that in fact I do know the drug's role". The reflection diary feedback teaching method provided students with a space to develop their interpersonal communication skills. The professional teachers guided them and provided feedback on their questions, helping them flexibly apply book knowledge to clinical practice, learn to use appropriate communication skills and communicate positively with patients and their families.

The study showed that students in the reflection diary writing condition had an easier time identifying the crux of a problem, analysing it, and predicting expected consequences; they were more curious and eager for knowledge, more prudent in making decisions or modi- 
fying existing decisions, and more open to a variety of solutions to methodological issues. For example, a student challenged the proposed nursing diagnosis of "anxiety" in a 32-year-old patient with breast cancer in her internship reflection diary. She believed that, considering various factors relevant to the nursing diagnosis of "anxiety" and the patient's fear of surgery, a comprehensive analysis of the patient's psychology, social environment and family context should be performed. It was found that the patient, who was a literary and art worker, was worried about the way the loss of one side of the breast after surgery would affect her image and influence her marriage relationship. Professional teachers affirmed the students' questions and guided them to use analysis, synthesis, evaluation and other critical thinking skills in clinical practice to adapt to a variety of complex situations and develop their ability to identify, analyse and solve problems.

In fact, the feedback process of checking, reflecting, summarizing and providing further teaching had benefits for teachers as well as students. The reflection diary feedback process provided teachers and students with an equal and sincere platform for teaching communication and emotional interaction and played a positive role in encouraging teachers and students. The nursing students self-assessed their clinical experience in their reflection diaries, analysed clinical events, expressed their feelings and attitudes and summarized their experiences and lessons, while discovering new ideas, information and questions from their experiences; the diary also gave them the opportunity to raise issues worthy of discussion and improve their ability to accumulate knowledge for enhancing their clinical practice in the future. Through this process, they achieved learning objectives and developed their ability to consciously choose the best service approach in their future nursing practice. Professional teachers were able to understand the learning situation and thought processes of the nursing students by reviewing their reflection diaries, as well as to identify problems their students were facing in clinical practice. This enabled them to foster reflection and comprehensively improve the quality of nursing education by enriching the teaching experience.

Although the contents of the diary may accurately reflect the feelings that the nursing students were experiencing, various confounding factors should be minimized to obtain factual information. The teacher should clarify the content that should be written in the reflection diary. Students' true feelings must be recorded. Teachers must keep sensitive issues expressed in the diary confidential and handle this information carefully so that the nursing students can write freely. However, since the reflection diary is given to teachers and reviewed, the Hawthorne effect is inevitable. Studies show that if the listener is the teacher, students tend to tell the story in the way they believed the teacher wants to hear it (18). If the listener is a companion, storytellers may be more truly open-minded and self-revealing (19).

Educators should create an environment of harmony and trust in which they give constructive feedback (20). Teachers should not impose their own ideas in reading and correcting the reflection diaries of nursing students, but rather encourage students to express different views and opinions freely. The importance is not to tell the truth, but rather to state the facts in a way that leads to reflection and learning (19).

Teachers read the reflection diaries and give feedback in order to understand nursing students, while encouraging them to put forward their own solutions to the problems they encounter and to have the courage and wisdom to try their own approach (7). For example, students wrote in their reflection diaries that "a large gap existed between theory and practice in the clinical experience", but did not specifically describe where and why the gap existed. After the teachers read the reflection diaries, they should remind the students in a timely manner to reflect upon this observation. For each problem they encounter, the students should ask "why" and put forward their views. Reflection is not a description, quality is not quantity and safety is not a sanction (21).

Although both clerkship and internship belong to clinical practice, their nature is different. As such, the problems expressed during clerkship did not fully reflect all of the problems experienced in clinical practice. A reflection diary and feedback teaching loop is recommended, that is, the feedback provided on the problems expressed in nursing interns' reflection diaries should be taken into account when teaching the next cohort of students, thereby improving the overall quality of teaching in the nursing profession. Once nursing students are accustomed to writing their experiences in diaries, many may continue to use this mechanism during their nursing career (22).

In summary, nursing is a very practical subject and practical teaching therefore plays an important role. To improve the quality of practice teaching, educators must pay attention to feedback and conduct timely assessments of teaching effectiveness during the teaching process. 
The reflection diary feedback teaching method provides us with an evidence-based teaching method with broad application potential in the field of nursing education.

\section{AUTHORS' NOTE}

The authors declare that they have no conflicts of interest.

\section{REFERENCES}

1. Atkins S, Murphy K. Reflection: a review of the literature. J Adv Nurs 1993; 18: 1188-92.

2. Sheila E. The value of reflective journaling in undergraduate nursing education: A literature review. Int J Nurs Stud 2008; 45: 1379-88.

3. Mantsoukas S, Jasper MA. Reflective practice and daily ward reality: a cover power game. J Clin Nurs 2004; 13: 925-33.

4. Duke S, Appleton J. The use of reflection in a palliative care program: a quantitative study of reflective skills over an academic year. J Adv Nurs 2000; 32: 1557-68.

5. Kember D, Jones A, Loke A, Mckay J, Sinclair K, Tse H et al. Determining the level of reflective thinking from students' written journals using coding schemes based on the work of Mezirow. Int J Lifelong Educ 1999; 18: 18-30.

6. Riley-Doucet C, Wilson S. A three-step method of self-reflection using reflective journal writing. J Adv Nurs 1997; 25: 964-8.

7. Clandinin DJ, Connelly FM. Rhythms in teaching: the narrative study of teachers' personal practical knowlege of classrooms. Teach Teach Educ 1986; 2: 377-87.

8. Naber J, Wyatt TH. The effect of reflective writing interventions on the critical thinking skills and dispositions of baccalaureate nursing. Nurs Educ Today 2014; 34: 67-72.

9. Craft M. Reflective writing and nursing education. J Nurs Educ 2005; 44: 53-7.
10. Mc Guire L, Lay K, Peters J. Pedagogy of reflective writing in professional education. J Scholarship Teach Learn 2009; 9: $93-$ 107.

11. Bowman M, Addyman B. Academic reflective writing: a study to examine its usefulness. Br J Nurs 2014; 23: 304-9.

12. Howard J. The emotional diary-a framework for reflective practice. Educ Gen Prac 1997; 8: 288-91.

13. Mallik M. The role of nurse educators in the development of reflective practitioners: a selective case study of the Australian and UK experience. Nurs Educ Today 1998; 18: 52-63.

14. Nicholl H, Higgins A. Reflection in pre-registration nursing curricula. J Adv Nurs 2004; 46: 578-85.

15. Richardson G, Maltby H. Reflection-on-practice:enhancing student learning. J Adv Nurs 1995; 22: 235-42.

16. Williams RM, Wessel J, Gemus M, Seargeant EF. Journal writing to promote reflection by physical therapy students during clinical placements. Physiother Theor Pract 2002; 18: 5-15.

17. Wessel J, Larin H. Change in reflections of physiotherapy students over time in clinical placement. Learn Health Social Care 2006; 5: 119-32.

18. Paterson BL. Developing and maintaining reflection in clinical. Nurs Educ Today 1995; 15: 211-20.

19. Zannini L, Cattaneo C, Brugnolli A, Saiani L. How do healthcare professionals perceive themselves after a mentoring programme? A qualitative study based on the reflective exercise of "writing a letter to yourself. J Adv Nurs 2011; 67: 1800-10.

20. Shapiro J, Kasmas D, Shafer A. Words and wards: a model for reflective writing and its uses in medical education. J Med Hum 2006; 27: 231-44.

21. Kessler PD, Lund CH. Reflective journaling developing an online journal for distance education. Nurs Educ 2004; 29: $20-4$.

22. Sewell EA. Journaling as a mechanism to facilitate graduate nurses' role transition. J Nurs Staff Devt 2008; 24: 49-52. 